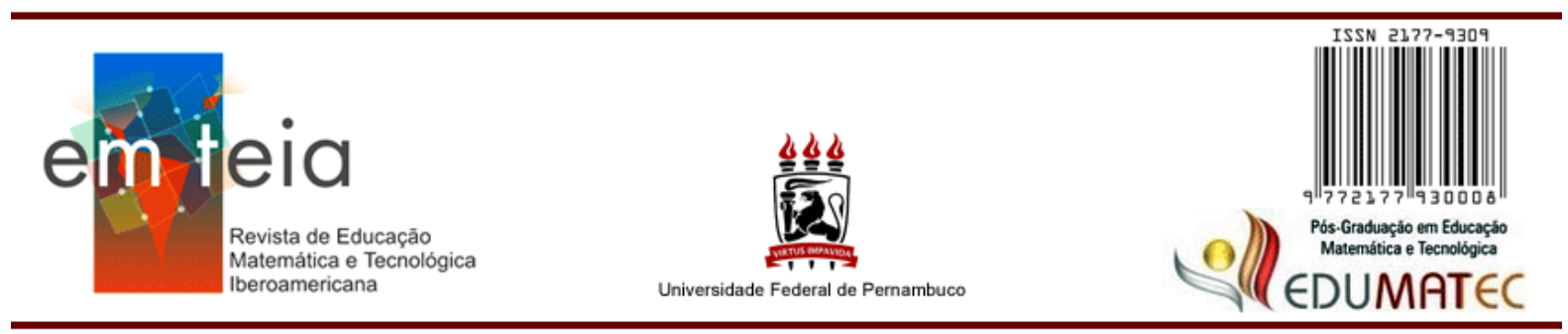

\title{
O QUE SE MOSTRA EM RELAÇÃO À EQUIDADE: a visão de professores que ensinam matemática nos anos iniciais
}

\author{
WHAT SHOWS ABOUT EQUITY: the view of teachers who teach mathematics in the \\ early years
}

Adriana Costa Santos da Silva

Mestranda em Educação em Ciências e Matemática Universidade Estadual de Santa Cruz - BA - Brasil adcssilva@uesc.br https://orcid.org/0000-0002-0027-893X

Marlúbia Corrêa de Paula

Doutora em Educação em Ciências e Matemática Universidade Estadual de Santa Cruz - BA - Brasil mcpaula@uesc.br

https://orcid.org/0000-0002-3646-8700

\author{
Maria Elizabete Souza Couto \\ Doutora em Educação \\ Universidade Estadual de Santa Cruz - BA - Brasil \\ mcouto@uesc.br \\ https://orcid.org/0000-0002-0026-5266
}

\begin{abstract}
Resumo
A equidade é definida como um conceito subjetivo, porém, possível por meio do acesso, da realização, da identidade e do poder. Este artigo tem por objetivo identificar como o professor de Matemática resume a ideia de equidade a partir de um fragmento da Base Nacional Curricular Comum (BNCC). O interesse por esse tema surgiu da percepção de que um sistema que nivela a todos por igual não dá conta de perceber as especificidades apresentadas pelos estudantes, as quais precisam, muitas vezes, de estratégias diferenciadas para possibilitar a aprendizagem. $\mathrm{O}$ contexto da pesquisa se configura em um período de pandemia da Covid-19, momento em que muitas pessoas se encontram em distanciamento social. Os participantes da pesquisa foram 18 professores que atuam nos anos iniciais da rede pública e particular de ensino de três cidades - Ilhéus, Itapetinga e Teixeira de Freitas. Os dados foram coletados pelo google forms. Para análise, utilizamos a metodologia de Análise Textual Discursiva (ATD). Conforme os resultados, cinco professores percebem a equidade como possibilidade de oferecer um ensino indicando estratégias para que a aprendizagem aconteça, oito percebem a equidade como igualdade, dois consideram como distante, três escrevem apenas uma palavra, o que dificulta o processo da análise. Os resultados sugerem que o tema deve ser mais debatido e vivenciado no contexto educacional.
\end{abstract}

Palavras-chave: equidade, educação, aprendizagem, professores, Matemática. 


\begin{abstract}
Equity is defined as a subjective concept, but possible through access, achievement, identity and power. This article aims to identify how the math teacher summarizes the idea of equity from a fragment of the Base Nacional Comum Curricular [Common National Curriculum Base] (BNCC). The interest in this theme arose from the perception that a system that leveled everyone equally does not take into account the specificities presented by students, who often need different strategies to enable learning. The context of the research is configured in a period of Covid-19 pandemic, a time when many people find themselves in social isolation. The research participants were 18 teachers who work in the early years of public and private education in three cities - Ilhéus, Itapetinga and Teixeira de Freitas. The data were collected by google forms. For analysis, we use the Análise Textual Discursiva [Discursive Textual Analysis] (ATD) methodology. According to the results, five teachers perceive equity as the possibility of offering teaching indicating strategies for learning to happen, eight perceive equity as equality, two consider it as distant, three write just one word, which makes the analysis process difficult. The results suggest that the theme should be more debated and experienced in the educational context.
\end{abstract}

Keywords: equity, education, learning, teachers, Mathematics.

\title{
Introdução
}

A Matemática, embora seja uma disciplina tão importante quanto as demais, pode constituir, por meio de sua aprendizagem, o atendimento de necessidades sociais, seja para resolver situações rotineiras do dia a dia, como pagar uma conta no supermercado, seja para resolver questões que atendam a outras necessidades que demandem resoluções para uma determinada coletividade. Pode ser, por exemplo, uma decisão a ser tomada sobre o condomínio de um prédio ou sobre o próprio coletivo de professores de uma escola. Entretanto, deixando de lado as especificidades, historicamente, a Matemática sempre foi apresentada como algo difícil e restrita a um pequeno grupo da sociedade. Desse modo, como se davam as resoluções de situações necessárias aos grupos que se situavam fora desse contexto?

Após considerar a comunidade escolar como um todo, ao qual se deve designar a organização dos conteúdos escolares, sem restrições ou particularidades, passamos a apresentar as ideias de equidade, a partir da Base Nacional Curricular Comum - BNCC (BRASIL, 2018). Este documento apresenta as desigualdades educacionais sob o ponto de vista de sua naturalização, no Brasil, em relação ao acesso à escola, à permanência e ao aprendizado.

Tais fatores, ao longo das décadas, foram constituídos gerando desigualdades que terminaram por caracterizar os grupos de estudantes definidos por raça, sexo, e aliando essas identificações à condição socioeconômica de suas famílias como um fator negativo para a 
permanência na escola. Sendo assim, diante deste quadro, as instituições escolares necessitam de um planejamento com foco na equidade.

Nesse sentido, no presente artigo, objetivamos identificar como o professor de Matemática resume a ideia de equidade a partir do seguinte fragmento da BNCC, mostrando que a "equidade supõe a igualdade de oportunidades para ingressar, permanecer e aprender na escola, por meio do estabelecimento de um patamar de aprendizagem e desenvolvimento a que todos têm direito" (BRASIL, 2018, p. 11).

Diante do exposto, trazemos as seguintes indagações: quais as contribuições de professores que ensinam Matemática, em salas de aula, nos anos iniciais, para que todos os alunos aprendam? E, ainda, o que esses professores descrevem como ações que podem propiciar a equidade nas salas de aula onde ensinam?

Quanto à estrutura, este artigo está organizado nos seguintes tópicos: a Educação Matemática e a equidade, a metodologia e o método de análise, que foi fundamentado na Análise Textual Discursiva (ATD), a discussão do material produzido na pesquisa e resultados.

\section{A Educação Matemática e a equidade}

Para D’Ambrósio (2011, p. 75) “a matemática se apresenta como um deus mais sábio, mais milagroso e mais poderoso que as divindades tradicionais e de outras culturas". Todavia, essa supervalorização contribuiu, ao longo do tempo, para o fortalecimento de um ambiente social baseado em exclusão e desigualdades desse conhecimento. Sendo assim, é preciso olhar para essa realidade de forma crítica buscando estratégias para transformá-la. Essa acepção está relacionada a uma realidade que nega a forma acabada. Portanto, dado o aceite sem qualquer reivindicação é o que esperamos superar ao propor uma educação que vá além da supervalorização de uma aprendizagem em prol de outra.

Considerando que todos têm direitos e precisam de oportunidades para aprender os conceitos matemáticos, os estudos de Silva, Marcone, Brião e Kistemann (2017) ajudam-nos a compreender a distância entre direito e oportunidade, a partir dos princípios da equidade que ressaltam a garantia de cenários promovedores de qualidade educacional, de modo a possibilitar a inserção dos estudantes no contexto escolar e na sociedade tecnológica em que estes se inserem, permitindo sua permanência e desenvolvimento como cidadão capaz de atuar e transformar seu contexto de forma crítica. 
É preciso mencionar que a equidade, discutida pelos autores, reconhece que nem todos aprendem ou podem usufruir de uma mesma metodologia de ensino e de aprendizagem. Dessa forma, a equidade, no contexto da Educação Matemática, significa promover ensino e aprendizagem para que os estudantes, independentemente de raça, origem, gênero ou classe social, tenham oportunidades de aprendizagens diferenciadas.

Desse modo, conforme Silva (2016), a equidade vem sendo discutida na Educação Matemática, desde 1980, como algo subjetivo. Segundo essa abordagem, a motivação desta compreensão decorreu, inicialmente, pela baixa representatividade de mulheres negras em cursos e empregos relacionados com a Matemática.

Em relação ao ensino da Matemática, para Gutiérrez (2012), a equidade perpassa por quatro dimensões, tais como: o acesso, a realização, a identidade e o poder. Para a autora, a dimensão acesso refere-se à disponibilidade de recursos para que os estudantes consigam compreender a Matemática como uma disciplina que faz parte do seu contexto.

A dimensão realização é evidenciada pela necessidade do envolvimento e participação dos grupos que são responsáveis por promover a educação (governo federal, estadual, municipal, professores, familiares e os próprios estudantes).

A dimensão identidade discute sobre os cuidados necessários para que não exista uma postura que minimize as capacidades pessoais, seja por fatores culturais ou linguísticos dos estudantes. Em relação aos fatores culturais, D’Ambrósio (2011) compreende que estão constantemente em transformação, seguindo ao que é possível nomear uma dinâmica cultural. Ressalta, também, que o comportamento e o conhecimento são maneiras de saber e fazer que estão em permanente interação.

Sobre a dimensão de poder, a autora destaca a possibilidade de agir sobre o mundo em que estamos inseridos, compreendendo como o diferencial para o processo, pois agir sobre o mundo significa buscar o seu lugar, sentir-se importante e útil para a sociedade. Tal dimensão perpassa por questões de transformação social em diferentes níveis, que ultrapassam o contexto de sala de aula.

Nesse sentido, D’Ambrósio (2011, p. 66) afirma que:

[...] a boa educação não será avaliada pelo conteúdo ensinado pelo professor e aprendido pelo aluno. [...] Espera-se que a educação possibilite aos educandos a aquisição e utilização de instrumentos comunicativos, analíticos e materiais que serão essenciais para seu exercício de todos os direitos e deveres intrínsecos à cidadania. 
As quatro dimensões discutidas estão conectadas a dois eixos de significado, os quais constituem as várias abordagens utilizadas na Educação Matemática que buscam atingir o processo de equidade: o eixo dominante e o eixo crítico.

O eixo dominante, do qual as dimensões de acesso e realização fazem parte, enfatiza que as pessoas menos favorecidas socialmente devem possuir meios para aprender a Matemática, que é amplamente apreciada e que habilita o estudante a participar ativamente no contexto social ao qual está inserido. Já o eixo crítico, constituído pelas dimensões de identidade e poder, trata do desenvolvimento de habilidade que prepara o estudante para as questões da Matemática (GUTIÉRREZ, 2012).

Nesse sentido, para Antunes e Silva (2015), a equidade acontece na escola a partir do envolvimento dos gestores e, principalmente, dos professores, na medida em que a eficácia dos processos educativos é percebida pelos estudantes por meio da proximidade existente entre as pessoas envolvidas e pelas características, disposições e ações para conferir qualidade e garantir continuidade a esses processos.

Enquanto Soares, Santos e Lopes (2020, p. 1) compreendem que "a equidade é uma condição necessária a todo ser humano para assegurar a sua dignidade”, conforme Carrijo (2014), a formação para a cidadania está no centro das reflexões nas diversas áreas da sociedade, em especial no campo educacional. O tema aparece nos debates sobre o modo como a educação deve ser organizada, as intenções do que ensinamos e que tipo de pessoas pretendemos formar, principalmente ao desejar o rompimento com as reproduções sociais fortemente caracterizadas pelas desigualdades, opressões e desrespeito às diversidades.

No que condiz ao tema equidade, a Base Nacional Curricular Comum - BNCC (BRASIL, 2018), documento estabelecido para todo o Brasil, traz o mesmo ponto de partida, tanto para as escolas públicas como para as escolas particulares, ou seja, leva em consideração que a aprendizagem deve ser desenvolvida independentemente das diferenças sociais presentes. Porém, este documento oferece abertura para que cada município, junto às Secretarias de Educação, faça as suas adequações de acordo com o seu contexto e realidade, evidenciando, com isso, características da equidade no sentido de tratar os diferentes de forma diferente, respeitando suas particularidades e apontando para os direitos de aprendizagem.

Sendo assim, de acordo com Gutiérrez (2012), os aspectos que estão presentes na perspectiva dominante e crítica contribuíram em sua tentativa de compreender equidade, pois consideram não apenas os resultados da aprendizagem tratada em um contexto escolar, uma vez que direcionam resultados que se associam com a vida e com os relacionamentos 
existentes. Ainda buscando conceituar a equidade na Educação Matemática, a autora destaca três abordagens: uma materialista, uma liberalista e uma pós-estruturalista.

O materialismo busca compreender a mudança do mundo a partir da realidade material; o liberalismo defende que todos devem ter oportunidades justas de sucesso; o pósestruturalismo desconstrói a ideia de verdade absoluta em relação ao sujeito e enfatiza a complexidade do ser humano. Nesse sentido, vale lembrar que "a Educação Matemática poderia desempenhar um papel importante no desenvolvimento da cidadania crítica" (SKOVSMOSE, 2007, p. 176).

Nessa direção, Skovsmose (2007) entende que a Educação Matemática pode promover possibilidades para que o sujeito consiga utilizar os conhecimentos em diferentes contextos, de modo que possa se perceber e agir como cidadão crítico e atuante socialmente. O autor propõe que o conhecimento das habilidades matemáticas, o conhecimento das tecnologias e o conhecimento reflexivo são fundamentais para que o desenvolvimento da matemática seja compreendido.

Destarte, Pais e Valero (2012) pontuam que para atingir a equidade na Educação Matemática, é preciso questionar o sistema como um todo, tendo consciência de que todos os problemas particulares que tentam resolver dentro da Educação Matemática não mudarão, sem pensar em políticas públicas que contemplem questões básicas como: moradia, saúde e alimentação. Tais políticas precisam atender às necessidades sociais, pois o processo de aprendizagem não depende apenas de o estudante estar na escola e ter um professor, mas de um conjunto de situações que estruturam a vida de qualquer pessoa. Os autores consideram que expressões como qualidade, justiça social e diversidade têm sido amplamente relacionadas com a equidade em práticas de sala de aula, pesquisas e em novas propostas curriculares.

As discussões que Silva (2016), Gutiérrez (2012) e Pais e Valero (2012) fazem são essenciais, pois, embora pareçam ser temáticas antigas, ainda são necessárias publicações no sentido de que os estudantes concluam o ano letivo com as habilidades e competências para continuar avançando em seus estudos. Convém observar sobre o modo como a Matemática é ensinada atualmente, visto que não mudou muito em relação ao tempo em que esses autores propuseram tais reflexões. Dessa forma, continuamos a ver uma Matemática dominante, ou seja, uma Matemática para poucos e, ao refletir sobre as desigualdades na aprendizagem em Matemática, muitas vezes, parece que nivelar os conhecimentos dos estudantes, oferecendo as mesmas oportunidades de ensino e o mesmo tratamento, possa ser algo justo. Entretanto, em 
muitas situações, a igualdade na oferta das situações e dos conteúdos pode ser insuficiente e, por isso, injusta.

Destarte, Kasmirski, Gusmão e Ribeiro (2017) lembram que os estudantes devem ter acesso ao que a sociedade definiu como necessário a ser aprendido, de modo que tenham garantidas sua dignidade, autoestima e trajetória escolar menos turbulenta, diminuindo, assim, a desigualdade escolar e social. Como exemplo dessa situação, conforme sugere Sandel (2014), participar de uma corrida é algo agradável, porém se a corrida iniciar em pontos de partida diferentes, dificilmente teremos uma corrida justa. Essa situação também acontece no ensino e na aprendizagem dos conceitos de Matemática. Os mesmos exemplos, as mesmas atividades nem sempre ajudarão na aprendizagem dos alunos. Enuncia também que, em muitos casos, a sociedade busca remover os obstáculos que se opõem à igualdade de oportunidades entre as pessoas de grupos ou de níveis sociais diferentes, criando programas assistencialistas de saúde, educação e treinamento profissional.

Para compreender a reflexão realizada por Sandel (2014), queremos ressaltar que desde a segunda metade do século XX, John Rawls, filósofo e político norte-americano, já percebia que mesmo retirando os obstáculos, a corrida tende a continuar desigual, sendo que podemos indicar facilmente aqueles que sairão vencedores. Dessa forma, Rawls (2003) sugere uma justiça como equidade, sendo a distribuição desigual entre as habilidades e as aptidões das pessoas.

Ao pensar na equidade na aprendizagem do ensino da Matemática, deve ser levado em consideração o contexto da escola, em que as salas de aulas são formadas por crianças/adolescentes que têm conhecimentos diferentes. Nesse momento, temos um público heterogêneo composto por crianças que apresentam algum tipo de necessidade especial (surdos, cadeirantes, autistas etc.), crianças filhas de pais trabalhadores, pertencentes às classes sociais média e baixa; crianças que dependem da escola e da forma como esta realiza um trabalho diferenciado que contribua para possíveis alterações no ciclo de aprendizagem.

\section{Metodologia: do perfil dos professores ao detalhamento de ATD}

Ao tratar da metodologia da pesquisa, é preciso pensar na realidade que propõe a superação da descrição, interpretação e atinge a competência exploratória, conforme Richardson (2014), ao considerar os planos de pesquisa que devem ser percorridos pelo pesquisador. Nisso, pressupomos que para assumir a condução de uma pesquisa acadêmica, ou para resolver determinado problema social, na comunidade em que estamos inseridos, é 
necessário reconhecer uma forma de realidade na qual não coexistem saberes diferenciados para os grupos, mas sim saberes compartilhados pelos grupos. Ainda, no que tange à questão do termo 'realidade', Lincoln e Guba (1985) enunciam quatro reconhecimentos de realidade: objetiva, percebida, construída e criada.

Em relação à realidade objetiva, fazem considerações sobre compreensões que derivam do senso comum, e nisso, embora tenha aceitação e uso, se constitui como précrítica, para quem assim percebe o mundo, o único caminho é aceitar o que está dado.

No entanto, a realidade percebida admite a existência a partir da objetiva. Partindo desta, a realidade percebida é parcial e admite uma relação de dependência para com cada homem. Enquanto na realidade construída se pode supor que, dada a complexidade do mundo, o homem age supondo outras possibilidades e nisso constrói suas ações. Então, podemos pensar sobre determinadas perspectivas que podem ser consideradas ou não, mas que ainda assim colocam esse homem em um patamar diferente daquele que é tido como précrítico. E para fechar a contribuição sobre realidade, os autores enunciam uma realidade criada, a qual se assume como crítica e resulta da superação das demais.

Considerando essa realidade, foi desenvolvida uma pesquisa de abordagem qualitativa com 18 professores da rede pública e privada das cidades de Ilhéus, Itapetinga e Teixeira de Freitas, no interior do Estado da Bahia, que responderam ao questionário semiestruturado, com quatro questões, enviado por meio do Google Forms.

Para Richardson (2014, p. 189), "Existem diversos instrumentos de coleta de dados que podem ser utilizados para obter informações acerca de grupos sociais. O mais comum entre esses instrumentos talvez seja o questionário". A escolha pelo questionário, como instrumento de coleta, se deve ao momento de pandemia vivenciado no Brasil, desde o ano de 2020. Desde que iniciou esse período, foram adotadas medidas de contenção, como o distanciamento social, para evitar a disseminação em massa do agente causador da COVID-19 (doença que advém da infecção causada pelo contato com o coronavírus), e têm sido mantidas até que exista a possibilidade de aplicação das vacinas.

Dessa forma, os professores responderam aos questionamentos e após fizeram a devolução via Google Forms.

\section{Perfil dos professores participantes}

A coleta de dados foi realizada com 18 professores que lecionam em todos os anos iniciais (do $1^{\mathrm{o}}$ ao $5^{\circ}$ ) do Ensino Fundamental, conforme Quadro 1. Desse grupo, 12 
professores possuem especialização Lato Sensu, não havendo professores com o curso de Mestrado. Quanto à faixa etária, há dois professores com idade entre 21 e 30 anos, cinco com idade entre 31 e 40 anos, sete professores com 41 a 50 anos e quatro com mais de 51 anos. Quanto ao ano escolar em que esses professores lecionam são: cinco ensinando o $1^{\circ}$ ano, dois no $2^{\circ}$ ano, três no $3^{\circ}$ ano, dois no $4^{\circ}$ ano e seis no $5^{\circ}$ ano.

Quadro 1 - Perfil dos participantes da pesquisa

\begin{tabular}{|c|c|c|c|c|c|c|c|c|c|c|c|}
\hline & \multicolumn{4}{|c|}{ Idade } & \multicolumn{2}{|c|}{ Formação } & \multicolumn{5}{|c|}{ Ano escolar que leciona } \\
\hline & 1 a 30 & 1 a 40 & 0 a 50 & +51 & Graduação & Especialização & $1^{0}$ & $2^{\circ}$ & $3^{\mathbf{o}}$ & $4^{0}$ & $5^{\circ}$ \\
\hline Qtde. & 2 & 5 & 7 & 4 & 6 & 12 & 5 & 2 & 3 & 2 & 6 \\
\hline Total & \multicolumn{4}{|c|}{18} & \multicolumn{2}{|r|}{18} & \multicolumn{5}{|c|}{18} \\
\hline
\end{tabular}

Fonte: elaborado pelas autoras (2020).

O contato inicial com os participantes da pesquisa aconteceu por meio de mensagem no WhatsApp e, por esse mesmo recurso, enviamos o link do questionário para 20 professores de Ilhéus, Itapetinga e Teixeira de Freitas, cidades localizadas nas regiões sul, sudoeste e extremo sul da Bahia. Dessa forma, os participantes tiveram cinco dias para respondê-lo. Isso foi possível, porque uma das pesquisadoras conhecia os professores selecionados para a pesquisa.

\section{Detalhamento de ATD: Análise dos dados qualitativos}

Os dados analisados neste momento advêm das contribuições realizadas pelo grupo de professores, acima delineado. Desse modo, os professores responderam a uma indagação sobre equidade, a qual será mencionada no Quadro 2, na sequência deste tópico. Para enunciar as etapas da ATD é preciso considerar o que Moraes e Galiazzi (2011) discorrem sobre esta metodologia. Com a finalidade de detalhamento, a ATD se constitui de unitarização, categorização e metatexto. Cada uma das etapas requer uma breve explicitação quanto às características que as constituem. A unitarização é a etapa em que se dá a desconstrução das contribuições. Nesse momento, cada uma das respostas foi particionada de acordo com a 
interpretação e as leituras realizadas. Na ATD, essas partições são chamadas de unidades de análise.

Após essa etapa, tem início a categorização, mas esse processo não ocorreu de uma só vez, pois a obtenção de categorias se dá mediante três etapas: inicial, intermediária e final. $\mathrm{Na}$ sequência da metodologia de análise, a ATD encaminha-se ao final quando ocorre a escrita do Metatexto. Para constituir o metatexto, é necessário que se dê a interlocução obtida na escrita das categorias finais, o referencial teórico e a opinião crítica dos pesquisadores. Neste artigo, atendendo a essa necessidade metodológica, assim foi realizado. Desta 'costura' decorreu a formação do último momento da ATD: o captar e comunicar do novo emergente, neste texto que se obtém de outros textos: o metatexto.

\section{ATD realizada sobre as contribuições: categorização}

O procedimento para a obtenção de categorias demanda três momentos, conforme anteriormente apresentado. No quadro 2, apresentamos um recorte dos procedimentos realizados.

Quadro 2 - Recorte do procedimento de unitarização e categorização sobre as contribuições dos professores

\begin{tabular}{|c|c|c|c|c|c|}
\hline Professores & Unitarização & Categorias iniciais & \begin{tabular}{|l|} 
Categorias \\
intermediárias
\end{tabular} & $\begin{array}{l}\text { Categorias } \\
\text { Intermediárias }\end{array}$ & Categoria Final \\
\hline $\begin{array}{l}\text { P1 Compreendo equidade } \\
\text { na educação como a } \\
\text { promoção de condições } \\
\text { adequadas para o } \\
\text { desenvolvimento de } \\
\text { habilidades } \\
\text { competências de acordo } \\
\text { com o que cada sujeito } \\
\text { precisa para aprender, }\end{array}$ & $\begin{array}{l}\text { P1 Compreendo } \\
\text { equidade na educação } \\
\text { como a promoção de } \\
\text { condições adequadas } \\
\text { para o } \\
\text { desenvolvimento de } \\
\text { habilidades e } \\
\text { competências } \\
\text { P1 de acordo com o } \\
\text { que cada sujeito }\end{array}$ & $\begin{array}{l}\text { P1; P2; P3; P4; P5; P6; } \\
\text { P7; P8; P9; P10; P11; } \\
\text { P12; P13; P14; P15; P16; } \\
\text { P17; P18 } \\
\text { Equidade é oferecer } \\
\text { oportunidade para o } \\
\text { desenvolvimento de } \\
\text { habilidade e } \\
\text { competências }\end{array}$ & $\begin{array}{l}\text { Equidade é } \\
\text { - Oferecer oportunidade; } \\
\text { - Respeitar diferenças de } \\
\text { aprendizagem; } \\
\text { - Condições físicas e } \\
\text { materiais para aprender; } \\
\text { - Desigualdade } \\
\text { educacional e social do } \\
\text { Brasil; }\end{array}$ & $\begin{array}{l}\text { Aprendizagem } \\
\text { Condições } \\
\text { Desigualdade }\end{array}$ & Equidade \\
\hline
\end{tabular}

Fonte: elaborado pelas autoras (2020)

No quadro acima, houve a explicitação de alguns dos momentos da análise. Por isso, aparecem duas colunas com categorias intermediárias, uma vez que todas as categorias passam por reescritas - idas e vindas - em função de (re)leituras. Dessa forma, não se trata de duas colunas de categoria distintas, mas da apresentação de um desses momentos de ajustes realizados para obter as categorias intermediárias. A opção se deu por conta desta exposição, mas poderia ter sido realizada em qualquer momento da fase de obtenção das categorias iniciais e finais. Ao concluir esta etapa teve início a escrita do Metatexto. 


\section{Metatexto}

Pensando na equidade sob a perspectiva da aprendizagem, trazemos exemplos de como isso pode acontecer no contexto educacional, no sentido de criar possibilidades para que os estudantes consigam aprender a partir de atividades elaboradas para atender a necessidade de cada um. Em nossas escolas encontraremos estudantes que aprendem e avançam em um ritmo considerado normal, mas há aqueles que apresentam dificuldades na leitura, na escrita e no raciocínio matemático, e aqueles com deficiência visual, auditiva, com autismo, entre outras especificidades. Todavia, para cada um destes estudantes, a forma de lidar será diferenciada, para que consigam êxito na vida escolar.

Conforme descreve P1: "Compreendo equidade na educação como a promoção de condições adequadas para o desenvolvimento de habilidades e competências". Contudo, não é possível tentar definir equidade partindo da igualdade, como fazem P7 e P8, respectivamente: "Condições iguais para o acessar, aprender e permanecer no ambiente escolar" e "Permitir ao aluno o acesso à aprendizagem". Para P14, a "Equidade surge do conceito de proporcionar a igualdade de aprendizado".

De acordo com Moraes e Galiazzi (2011), é necessário reconhecer que vivemos em um contexto que envolve diversas diferenças sociais. Diante dessa ideia, não podemos simplesmente estabelecer a igualdade apenas por meio de ações educativas. Pois, dada a manutenção das desigualdades sociais, ações educacionais atuam em desvantagem sobre locais e pessoas que se encontram fora do alcance de uma estrutura mínima, que trate de garantir a própria sobrevivência.

Por isso, Skovsmose (2008) afirma que a Educação Matemática possui um movimento constante de construção, visando incentivar o estudante a elaborar formas de pensar que o levem a refletir e agir de maneira crítica, permitindo-lhe pensar a cidadania por diversos ângulos e não apenas a partir do trabalho, sendo assim, "se cidadania significa participar do mercado de trabalho de uma sociedade, ser submisso a ordens pode ser uma preparação feita pela escola para a cidadania" (SKOVSMOSE, 2008, p. 94).

Assim, consideramos pensar a equidade no sentido de busca e reconhecimento de possibilidades de alcance, e a impossibilidade nos faz entender que, para pensar a educação na constituição do sujeito, é preciso compreender que o conhecimento não se restringe apenas à modalidade científica ou a ambientes formais de educação (CARRIJO, 2014). Portanto, é pertinente refletir sobre o que advém de uma das contribuições, pois a equidade não é uma 
falácia, como P11 descreve: “a equidade torna-se uma falácia ou uma ideia distante de ser alcançada".

Nesse sentido, pensando a equidade de forma global, acaba ficando distante mesmo, porém, ao partirmos da ideia de Antunes e Silva (2015), isso é possível. Isso porque esses autores visualizam a equidade na ação dos professores que exercem influência nos seus contextos de trabalho com seus alunos e colegas, relacionando a ação pedagógica que pode conduzir à aprendizagem e, dessa forma, ao fomento da equidade e da justiça social. Percebemos com isso que é possível desenvolver ações dentro de um contexto local e com um público menor. Estaremos, dessa forma, construindo conhecimento que, mais tarde, poderá ser compartilhado entre os familiares e amigos destes estudantes. Conforme D’Ambrósio (2011, p. 18), “Todo indivíduo vivo desenvolve conhecimento e tem um comportamento que reflete esse conhecimento, que por sua vez vai-se modificando em função dos resultados do comportamento".

Ainda, referente à equidade, P15 "percebe que é uma ideia apenas. Que diante da realidade vivida, está muito longe de ser alcançada". É preciso cuidar para que esse tipo de pensamento não nos desvie enquanto profissionais e, para isso, na docência devemos planejar o melhor para que o ensino e a aprendizagem aconteçam, dentro do possível, com excelência em nossas salas de aula. Sobre isso, Antunes e Silva (2015) compartilham a ideia de que a ação pedagógica do professor pode colaborar para o exercício da equidade na escola, quando assume o papel de liderança junto aos estudantes e colegas. Sendo assim, os autores esclarecem, ainda, que a liderança sustentável é mais do que uma reformulação das atividades, significando antes uma mudança de cultura que leva à mudança de atitude em favor da aprendizagem dos alunos e do crescimento de cada um, sendo a essência da equidade e a base possível da promoção da justiça social.

Portanto, concordamos com P10 quando diz: "Equidade não se refere apenas ao ponto de chegada". Realmente, equidade é uma caminhada a qual todos devem percorrer, não só porque somos profissionais da área de educação, mas porque somos cidadãos. Com essa prerrogativa é que pensamos no outro e, acima de tudo, desejamos uma sociedade melhor para viver. Porém, essa sociedade melhor só será possível quando tirarmos o foco das dificuldades e nos direcionarmos para as possibilidades. Essas questões não podem se situar num plano ideal, mas numa análise crítica das necessidades que precisam ser atendidas para que a estrutura que mantém os alunos e suas famílias condicionados à determinada falta de acesso seja rompida. 


\section{Resultados}

Sem dúvida, o ano de 2020 já entrou para a história de quase todos como o ano em que muitos profissionais precisaram se reinventar para continuar a realizar seus trabalhos, fato que não foi diferente para os profissionais da educação, pegos de surpresa no mês de março. Nesse período, quando mal havia iniciado o ano letivo, escolas e universidades tiveram as atividades suspensas ou redirecionadas, pois o mundo estava vivendo o medo, o pavor de um vírus desconhecido que logo recebeu o nome de coronavírus, o qual causa a Covid-19.

Diante desse cenário, nos propomos a realizar este trabalho visando identificar como 18 professores de Matemática resumem a ideia de equidade a partir do que é proposto na BNCC (BRASIL,2018, p. 11), em que a "equidade supõe a igualdade de oportunidades para ingressar, permanecer e aprender na escola por meio do estabelecimento de um patamar de aprendizagem e desenvolvimento a que todos têm direito". Esse documento traz uma contribuição à Educação, ao propor que o termo "equidade" seja discutido amplamente e, aos poucos, possam ser dirimidas as dificuldades presentes em salas de aula e escolas. Vencer as questões que tornam esse equilíbrio ainda revestido de incompreensões passa por compreender a formação do aluno num contexto cidadão, portanto, com teor de uma realidade crítica. Nisso, importa criar ou registrar questões e tentar resolver a partir e para o interesse daqueles que se encontram em sala de aula, buscando compreender processos, argumentações e comunicações.

Diante das contribuições analisadas, com uso de ATD, foi possível aproximá-las ao que Silva (2016) propõe sobre o conceito da equidade, tratando-o como algo subjetivo. A partir dessa consideração, retornamos para comunicar sobre o que se mostrou sobre a equidade, em atendimento ao objetivo dessa busca. Com isso, após a análise das contribuições de 18 professores que ensinam Matemática nos anos iniciais, foram identificados: cinco professores consideram a equidade a partir da promoção de possibilidades para que os estudantes alcancem a aprendizagem; oito percebem a equidade como igualdade; dois não acreditam na possibilidade de a equidade acontecer na Educação, e a situam como uma falácia; três professores se restringiram a afirmar que a equidade é algo necessário, importante e que concordavam com o texto proposto pela BNCC.

Em termos de interpretações realizadas sobre essas contribuições, podemos afirmar que todas se situam numa leitura descritiva ou interpretativa da realidade, o que evidencia o aspecto de circunstância, quanto à dificuldade que se mostrou sobre a compreensão referente 
ao que significa o conceito de equidade, pois não ocorreu uma contribuição no plano exploratório desse conceito. Por conseguinte, o excerto da BNCC, sobre o qual os questionamentos foram realizados, se mostrou ainda desconhecido por esses professores. Então, esse 'desconhecer' remeteu à obtenção da categoria final, que retomou o próprio interesse da busca, quando se desejava saber sobre o que se mostrava sobre equidade a partir das contribuições desses professores.

Por conclusão, após esta busca em relação à análise realizada, ao retomar o termo equidade presente ao final da categorização, consideramos que ocorreu presunção dos professores sobre o domínio desse conceito. Isso levou o retorno da análise ao termo já utilizado na própria indagação, pois ocorreu uma circularidade sem demonstrar avanços sobre as apropriações do conceito. Isso porque, ao serem questionados sobre equidade, surgiram termos como "falácia", ou ainda, "é algo necessário", denotando condução de superficialidade destas apropriações. Embora os elementos identificados em categorias iniciais possam dar conta do conceito de equidade, estes termos não conseguem atender ao significado impregnado, sendo tratados como subjetivo, justo pela possibilidade de considerá-lo singular em cada caso, e não por admiti-lo por impossível de ser estabelecido.

Assim, sem o estabelecimento de uma leitura crítica da realidade, como pressupõe Lincoln e Guba (1985), poderá ocorrer que os conceitos presentes em documentos oficiais não cheguem a ser discutidos e implementados junto às metodologias de salas de aula, pois, quando a equidade é compreendida como algo a ser estabelecido, para um grupo, e não para o grupo, é porque algo ainda está truncado nessa compreensão. À vista disso, a BNCC (2018) oportuniza que essas discussões se tornem efetivas dentro das escolas e dos planejamentos que lá se situam, posto que é uma evidência sobre a importância da implementação desse documento, o qual advém, neste artigo, também como fruto da análise realizada.

\section{Referências}

ANTUNES, R.R.; SILVA, A. A liderança dos professores para a equidade e a aprendizagem. Revista Lusófona de Educação, n. 30, 2015.

BRASIL. Ministério da Educação. Secretaria de Educação Básica. Base Nacional Comum Curricular. Brasília: MEC/SEB, 2018.

CARRIJO, M.H.S. O resgate do poder social da matemática a partir da Educação Matemática crítica: uma possibilidade na formação para a cidadania. Revista Paranaense de Educação Matemática, Campo Mourão, PR, v. 3, n. 5, jul./dez. 2014. 
D’AMBRÓSIO, U. Etnomatemática: elo entre as tradições e a modernidade. 4. ed. 1 reimp. Belo Horizonte: Autêntica, 2011.

GUTIÉRREZ, R. Context matters: how should we conceptualize equity in mathematics education? In: HERBEL-EISENMANN, B. et al. (Ed.). Equity in discourse for mathematics education: theories, practices, and policies. London, New York: Springer Netherlands, 2012. p. 17-33.

KASMIRSKI, P.; GUSMÃO, J.; RIBEIRO, V. O Paic e a equidade nas escolas de ensino fundamental cearenses. Estudos em Avaliação Educacional, São Paulo, v.28, n. 69, p. 848872, set./dez. 2017.

LINCOLN, Y.; GUBA, E. Naturalistic inquiry. Beverly Hills: Sage, 1985.

MORAES, R.; GALIAZZI, M. C. Análise Textual Discursiva. 2. ed. Ijuí: Ed. Unijuí, 2011.

PAIS, A.; VALERO, P. Beyond disavowing the politics of equity and quality in mathematics education. In: ATWEH, B. et al. (Ed.). Mapping equity and quality in mathematics education. London, New York: Springer Netherlands, 2011. p. 35-48.

RAWLS, J. Justiça como equidade: uma reformulação. Tradução Claudia Berliner. São Paulo: WMF/Martins Fontes, 2003.

RICHARDSON, R. J. et al. Pesquisa social: métodos e técnicas. São Paulo: Atlas, 2014.

SANDEL, M. Justiça: o que é fazer a coisa certa. Tradução Heloísa Matias e Maria Alice Máximo. 13. ed. Rio de Janeiro: Civilização Brasileira, 2014.

SILVA, G.H.G.; MARCONE, R.; BRIÃO; G.F.; KISTEMANN JR., M.A. Educação Matemática crítica e preocupações urgentes: cenários promovedores de equidade e justiça social. Revista Paranaense de Educação Matemática, Campo Mourão, PR, v. 6, n. 12, p. 130-157, jul./dez. 2017.

SILVA, G. H. G. Equidade e Educação Matemática. Educ. Matem. Pesq., São Paulo, v.18, n.1, p. 397-420, 2016.

SKOVSMOSE, O. Desafios da reflexão em Educação Matemática crítica. Campinas, SP: Papirus, 2008.

SKOVSMOSE, O. Educação crítica: incerteza, matemática e responsabilidade. São Paulo: Cortez, 2007.

SOARES, D.M.M.; SANTOS, Joana D.A.; LOPES, R.V.N. COVID-19 e a educação nos sistemas de ensino: mapeamento normativo e a garantia da equidade em tempos de pandemia. Revista Observatório, v. 6, n. 3 (Especial 1), maio 2020. 